\title{
LETTERS
}

\section{Discharge outcomes and frailty}

The issue of frailty and risk of death after discharge is serious and concerning. $\mathrm{Li}$ and colleagues studied the impact of frailty on outcomes after surgery in older patients and identified a high risk of death and readmission related to frailty. ${ }^{1}$ One issue that was not discussed is nursing skill mix and its effect on planning for discharge or preventing deaths and readmissions.

Some provinces have dealt with the high cost of hospital care by reducing staffing budgets and replacing substantial numbers of registered nurse (RN) positions with licensed practical nurses (LPNs). There has also been a move to more parttime or casual nurse staffing, which also reduces the costs of employee benefits.

As a nurse educator, I find it increasingly difficult to find RNs to assign to our nursing students, because there are so few on the units. This reduces the ability of baccalaureate students to be mentored and to practise enacting the role and scope of their practice. This potentially erodes their potential to have an impact on health care outcomes. All of these changes can adversely affect patient outcomes through factors such as recognition of frailty and implementation of appropriate resources.

The RN and LPN roles are often viewed as interchangeable, and the RN may not be working to scope of practice. Some agencies have interpreted the scope of RN practice to mean that they should be moved to the desk to lead the team rather than provide direct care. Although RNs and LPNs can both perform similar tasks of daily care, the RN has additional preparation in areas such as pathophysiology, pharmacology, research and leadership. The RN role is therefore aimed at performing com- plex and holistic evidence-based case management, preventive versus reactive care, and coordination of services to meet patient needs. The RN considers the trajectory of the patient across the entire stay rather than just the day's needs.

Some agencies are attempting to address the continued need for the RN at the bedside by mixing RN and LPN care for every patient, with the RN responsible for the more complex patients and providing guidance to the LPN for potential issues that may arise. Unfortunately, in practice, they sometimes just split their assignments, and the LPN may be unprepared to note or prevent complications.

A synthesis of the available literature on RN skill mix concluded that higher ratios of RNs to LPNs result in shorter hospital stays, lower mortality rates and lower rates of readmission. ${ }^{2}$ A systematic review and meta-analysis on $\mathrm{RN}$ staffing concluded that an increase of 1 RN fulltime equivalent reduced the odds of death by $16 \%$ among surgical patients, $9 \%$ among patients in the intensive care unit and $6 \%$ in medical patients. ${ }^{3} \mathrm{~A}$ "failure to rescue" was noted on units with fewer RNs, in which health providers did not recognize early signs of deterioration. ${ }^{4}$ Another study examined the effect of skill mix on 30-day mortality. ${ }^{5}$ The researchers found that higher ratios of RNs to non-RNs, lower temporary and casual employment, and more collaborative nurse-physician relationships significantly reduced 30-day patient mortality.

We are also seeing a rising acuity of patients discharged into the community, ${ }^{6}$ as well as higher rates of readmission in at least 4 provinces. ${ }^{7}$ This shift taxes the limited resources of community health and long-term care. It is possible that more RN care could reduce the discharge acuity and risk of readmission if problems are recognized before discharge.
Although the study by $\mathrm{Li}$ and colleagues ${ }^{1}$ was not aimed at determining causative factors, it is important to examine the impact of skill mix as a factor in the readmission or deaths of frail older adults compared with those who thrived after discharge. Although reducing RN presence in hospital may address short-term costs, it could be argued that the cost to the patient, family and community is substantial. The issue of skill mix warrants further examination when mortality and morbidity are a potential consequence.

\section{Cathy J. Carter-Snell PhD RN}

Nurse educator, Mount Royal University, Calgary, Alta.

Cite as: CMAJ 2019 April 8;191:E402. doi: $10.1503 / \mathrm{cmaj} .71600$

\section{References}

1. Li Y, Pederson JL, Churchill TA, et al. Impact of frailty on outcomes after discharge in older surgical patients: a prospective cohort study. CMAJ 2018;190:E184-90.

2. Needleman J. Nursing skill mix and patient outcomes. BMJ Qual Saf 2017;26:525-8.

3. Kane RL, Shamliyan T, Mueller C, et al. The association of registered nurse staffing levels and patient outcomes. Systematic review and metaanalysis. Med Care 2007;45:1195-204.

4. Tourangeau AE, Cranley LA, Jeffs L. Impact of nursing on hospital patient mortality: a focused review and related policy implications. Qual Saf Health Care 2006;15:4-8.

5. Estabrooks CA, Midodzi WK, Cummings GG, et al. The impact of hospital nursing characteristics on 30-day mortality. Nurs Res 2005;54:74-84.

6. Ontario's action plan for health care. Toronto: Ontario Health; 2015. Available: www.health. gov.on.ca/en/ms/ecfa/healthy_change/docs/rep _healthychange.pdf (accessed 2019 Mar. 19).

7. Your health system: patients readmitted to hospital. Ottawa: Canadian Institute for Health Information; 2019. Available: https://yourhealthsystem.cihi. ca/hsp/inbrief.\#!/indicators/006/all-patients -readmitted-to-hospital/;mapC1;mapLevel2;/ (accessed 2019 Mar. 19).

Competing interests: None declared. 